ORIGINAL ARTICLE

\title{
Newspaper framing of fatal motor vehicle crashes in four Midwestern cities in the United States, 1999-2000
}

\section{S M Connor, K Wesolowski}

See end of article for authors' affiliations

.....................

Correspondence to: Dr Susan M Connor, Rainbow Community Safety and Resource Center, Rainbow Babies and Children's Hospital, 11100 Euclid Ave, WRN B47, Cleveland, $\mathrm{OH}$ 44106-6039, USA; smc3@cwru.edu

\begin{abstract}
Objective: To examine the public health messages conveyed by newspaper coverage of fatal motor vehicle crashes and determine the extent to which press coverage accurately reflects real risks and crash trends. Methods: Crash details were extracted from two years of newspaper coverage of fatal crashes in four Midwestern cities in the United States. Details and causal factors identified by reporters were compared to data from the National Highway Traffic Safety Administration's Fatality Analysis Reporting System (FARS) using odds ratios and two tailed $z$ tests.

Results: Papers covered 278 fatal crashes over the two year period, in contrast to 846 fatal crashes documented in FARS. Papers assigned blame in $90 \%$ of crashes covered, under-reported restraint use and driver's risk of death, failed to reflect the protective value of restraints, and misrepresented the roles played by alcohol and teen drivers.

Conclusion: Newspaper coverage did not accurately reflect real risk. Papers presented fatal crashes as dramas with a victim/villain storyline; in keeping with this narrative strategy, papers were most likely to cover stories where a driver survived to take the blame. By highlighting crashes that diverge from the norm, focusing on the assignment of blame to a single party, and failing to convey the message that preventive practices like seatbelt use increase odds for survival, newspapers removed crashes from a public health context and positioned them as individual issues. Public health practitioners can work with media outlets in their areas to draw attention to misrepresentations and change the way these stories are framed.
\end{abstract}

$\mathrm{T}$ he news media has a key role in shaping the general public's health beliefs, but the media's choices of what stories to cover and how to cover them are driven by economic interests rather than public education goals. ${ }^{12}$ While the perceptions of the public, as well as policy makers, about the prevalence and nature of public health issues are influenced by the amount and type of coverage they receive in the popular press, editorial decisions about "newsworthiness" often are based on a story's novelty and dramatic value. $^{3-5}$ A barrage of press coverage can make a miniscule health threat-such as contracting HIV from a dentist or West Nile from a blood transfusion-feel more immediate and more serious to readers and viewers than the health hazards they are far more likely to encounter.

In the United States, motor vehicle crashes are a leading cause of death across the lifespan, and particularly for individuals from 1 to $34 .^{6}$ Press coverage of fatal motor vehicle crashes has the potential to shape readers' perceptions of personal risk and their beliefs about the nature and causes of crashes through the frames they employ, including the choice of which stories to cover and how much space to allot them, the narrative forms used in telling stories, the choice of detail, rhetorical strategies used, and the context in which information is placed. ${ }^{78}$ While there is a large body of research related to media coverage of other injury topicsparticularly homicide-there have been no examinations of media coverage of motor vehicle crashes and its potential impact on the public's knowledge and understanding of this health issue.

Media and public health goals are often at odds, since the former focuses on emphasizing the distinctiveness of the event covered and the latter aims to detect trends and similarities and identify risk factors. Examinations of television and newspaper reporting related to both disease outbreaks and lethal violence have found that the media's focus on rarity and drama and the reliance on identifying blame leads to the promotion of inaccuracies and the creation of a distorted sense of risk for readers and viewers. ${ }^{3-14}$ The ability to identify a responsible party allows reporters to place a story in a recognizable narrative framework. Injury related stories are more likely to be covered when they are somehow out of the ordinary, allowing the press to assign blame and to concentrate on a "worthy" victim-in the case of homicide, usually white, very young or very old, and of high socioeconomic status. ${ }^{9}$ The potential public health impact of this practice is immense: by assigning blame to a specific person or group, playing up conflict to advance the story, presenting injuries as the result of egregious human error or bad luck, and ignoring larger social and economic implications, injury related stories may be framed as individual issues and removed from a public health context, eliminating the need for prevention information. ${ }^{11}{ }^{14-16}$ If press coverage of fatal motor vehicle crashes follows this formula and routinely distorts public perceptions of the nature and consequences of traffic crashes, the stakes for public health are high.

This study examined print coverage of fatal motor vehicle crashes in four Midwestern markets in the United StatesChicago, Illinois; Columbus, Ohio; Cleveland, Ohio; and Milwaukee, Wisconsin-to gauge how well newspaper coverage of fatal motor vehicle crashes reflects real crash risk and to determine whether reporters take the opportunity to identify factors that mitigate the likelihood of injury, such as the use of seatbelts. The implications for public health professionals working to decrease morbidity and mortality related to this injury mechanism are discussed.

\section{METHODS}

The study was based on a convenience sample of four Midwestern cities in the United States. A Lexis-Nexis search

Abbreviations: $\mathrm{Cl}$, confidence interval; FARS, Fatality Analysis Reporting System; OR, odds ratio 
of articles published from l January 1999 through 31 December 2000 in the Chicago Sun Times, Columbus Dispatch, and Cleveland Plain Dealer was conducted using the following search terms:

(killed OR fatal) AND (traffic OR car OR auto*) AND (crash OR accident)

An identical search was conducted utilizing the Milwaukee Journal Sentinel's on-line public archives. National stories involving celebrities or sports figures were disregarded when residents of the paper's metropolitan area were not involved, since these stories tended to focus on individuals-NASCAR drivers Adam Petty and Kenny Irwin, for example, or Charlotte Hornets' guard Bobby Phills-and not on details of the crash. Searches of the National Highway Traffic Safety Administration's Fatality Analysis Reporting System (FARS) also were conducted for the home county of each newspaper (Cook County, Illinois; Franklin County, Ohio; Cuyahoga County, Ohio; and Milwaukee County, Wisconsin) to determine fatal crash trends in each metropolitan area. FARS data were obtained for crashes that included one or more motor vehicles in transport. The study was focused on real and perceived risk of death to motor vehicle occupants; as a result, crashes involving pedestrians and bicyclists were not included in analysis, since motor vehicle occupants are rarely the fatalities in these situations.

FARS data were not case matched with each crash covered in the individual newspapers. The purpose of the study was not to determine the extent to which each individual story was fact based, but to examine the bigger picture of crash risks, causes, and consequences created by the pattern of crash coverage in these papers.

Information on 40 individual data fields was extracted from articles. Captured data included the number of vehicles involved; the number of articles regarding any individual crash; driver age and gender; the number of times the terms "accident", "crash", "wreck", and "collision" were used as nouns to describe the event; whether the article assigned blame for a crash; whether the crash involved teen $(<20$ years of age) drivers; whether the article identified speed, alcohol/drugs, driver age, or weather/road conditions as factors; references to ejection and seatbelt use; and the number and ages of fatalities. A second analyst reviewed and coded a subset of stories and coding was compared with that of the primary reviewer. Disagreements were minor, primarily involving oversights by a coder; discrepancies were corrected and entries were recoded accordingly. Before analysis, data were recoded to combine multiple articles regarding the same crash so that data regarding a single incident would not be included more than once in analysis. In the combined database, numerical data regarding the use of proxy terms like accident or crash to refer to the incident were summed.

When articles identified an individual as being at fault in a crash, fault was coded as being implied or directly attributed. "Implied" indicated that a specific cause was noted, but was expressed passively (that is, "the car ran off the side of the road") or when blame was insinuated but not enough details
Table 2 Between-paper differences in under ( $\downarrow$ ) or over $(\uparrow$ ) reporting of crash problems, based on $z$ tests for significant differences in FARS/paper proportions ( $\leftrightarrow$ no significant difference in proportions)

\begin{tabular}{lllll}
\hline & Sun Times & Dispatch & $\begin{array}{l}\text { Plain } \\
\text { Dealer }\end{array}$ & $\begin{array}{l}\text { Journal } \\
\text { Sentinel }\end{array}$ \\
\hline $\begin{array}{l}\text { Proportion of } \\
\text { crashes which } \\
\text { involved teen } \\
\text { drivers }\end{array}$ & $\leftrightarrow$ & $\leftrightarrow$ & $\uparrow$ & $\uparrow$ \\
$\begin{array}{l}\text { Proportion of } \\
\text { crashes } \\
\text { described as } \\
\text { alcohol related }\end{array}$ & $\uparrow$ & $\leftrightarrow$ & $\leftrightarrow$ & $\leftrightarrow$ \\
$\begin{array}{l}\text { Proportion of } \\
\text { crashes where poor } \\
\text { road conditions } \\
\text { were noted }\end{array}$ & $\downarrow$ & $\downarrow$ & $\downarrow$ & $\leftrightarrow$ \\
\hline
\end{tabular}

were provided for the reader to visualize the crash: writing "Smith broadsided Jones' minivan" implies that Smith was at fault, but is inconclusive in the absence of other information about circumstances and right of way. Fault was coded as "directly attributed" when stories left no question of extenuating circumstances: "the driver lost control and the car ran off the side of the road" or "Smith ran a red light and broadsided Jones' minivan".

Intercommunity and intracommunity comparisons of FARS and newspaper data were conducted utilizing odds ratios and two tailed significance testing for comparison of means and proportions with SPSS 10.0; significance was defined as $p<0.05$. After determining differences in crash coverage and crash problems within the four markets, data from the four counties were combined and were tested for significant differences between the actual crash problem as described by FARS reports and the picture of the fatal crash problem painted by newspaper coverage in these areas.

\section{RESULTS}

The two year search identified a total of 278 crashes covered in the four papers and 846 crashes documented in FARS. Table 1 provides a breakdown of populations and crash risks for the four communities. There were some minor differences between papers in the emphasis placed on teens, alcohol, and road conditions (table 2), but overall the four periodicals provided readers with a similar picture of crash risks for individual drivers and analysis was based on combined data from the four communities.

Blame was assigned in $90 \%$ of crashes covered. Direct attribution of blame exceeded implication of blame in all papers, with an average direct to implied blame ratio of 5 . The mean number of stories devoted to each individual crash was 1.3. Crashes involving teen drivers were more likely to be covered by multiple stories (mean 1.65) than crashes where

Table 1 Breakdown of four markets studied and their respective crash problems

\begin{tabular}{|c|c|c|c|c|c|c|c|}
\hline City & County & $\begin{array}{l}\text { County population } \\
\text { (millions) }\end{array}$ & Newspaper & $\begin{array}{l}\text { No of fatal crashes } \\
99-00 \text { (FARS) }\end{array}$ & $\begin{array}{l}\text { Crash fatality } \\
\text { rate/ } 100000 \\
\text { pop } \geqslant \text { age } 15\end{array}$ & $\begin{array}{l}\text { No of crashes } \\
\text { covered in } \\
\text { paper }\end{array}$ & $\begin{array}{l}\text { Total No of crash } \\
\text { related stories in } \\
\text { paper }\end{array}$ \\
\hline Chicago, IL & Cook & 5.38 & Sun Times & 538 & 7.09 & 28 & 36 \\
\hline Cleveland, $\mathrm{OH}$ & Cuyahoga & 1.39 & Plain Dealer & 117 & 5.08 & 102 & 123 \\
\hline Columbus, $\mathrm{OH}$ & Franklin & 1.07 & Dispatch & 126 & 8.91 & 63 & 82 \\
\hline Milwaukee, WI & Milwaukee & 0.94 & Journal Sentinel & 65 & 5.19 & $85^{*}$ & 127 \\
\hline
\end{tabular}


Table 3 Results of two tailed tests for significant differences between FARS and newspaper crash data (bold indicates significant difference)

\begin{tabular}{llllr}
\hline Proportion of: & FARS & Papers & z Value & p Value \\
\hline Drivers who were male & 0.7671 & 0.7689 & 0.0624 & 0.9522 \\
Crashes where any occupant was described as restrained & 0.3837 & 0.0431 & 18.336 & $<0.0001$ \\
Drivers who were teens & 0.1383 & 0.223 & 3.3484 & 0.0005 \\
Crashes in which a driver was killed & 0.7837 & 0.3993 & 12.008 & $<0.0001$ \\
Crashes involving a single vehicle & 0.4326 & 0.3813 & 1.5035 & 0.1336 \\
Crashes in which any occupant was ejected & 0.2045 & 0.1583 & 1.6932 & 0.091 \\
Crashes described as alcohol related & 0.1868 & 0.2554 & -2.4637 & 0.0138 \\
Crashes described as alcohol related and involving teen drivers & 0.0213 & 0.036 & -1.3643 & 0.1738 \\
Crashes where poor road conditions were noted & 0.2139 & 0.0647 & 5.6541 & $<.0001$ \\
\hline
\end{tabular}

at-fault drivers were not teens $(t=-2.762, \mathrm{df}=243$, $\mathrm{p}=0.006)$.

All papers accurately reflected FARS data for the preponderance of male drivers involved in fatal crashes (77\%), the proportion of crashes that involved single vehicles (43\%), and the proportion of crashes where an occupant was ejected (20\%). Average driver age was 32.5 years (range 14-84), in keeping with the modal age range of 25-34 reported by FARS. The monthly distribution of fatal crash related stories published did not differ significantly from the monthly distribution of crashes in the FARS database.

Although papers accurately reflected the proportion of fatal crashes that involved the ejection of one or more occupants, they did not accurately portray the danger associated with ejection (see table 3 for results of significance testing of FARS/newspaper differences). According to FARS data, an ejected occupant had 6.3 times the odds of dying as an occupant who remained in the vehicle $(95 \%$ confidence interval (CI) 5.97 to 6.63). Based on newspaper descriptions of fatal crashes in these areas, ejected occupants had only 2.6 times the odds of unejected occupants of being killed (95\% CI 2.09 to 3.08 ).

Papers significantly under-represented risk to drivers, reporting that drivers were killed in only $40 \%$ of fatal crashes. In actuality, at least one driver was killed in $78 \%$ of fatal crashes. Based on FARS data, drivers had 2.5 times the odds of other occupants of being killed in a fatal crash $195 \%$ CI 2.37 to 2.72). According to newspaper coverage, drivers in general had only one fifth the odds of passengers of being among the fatalities (odds ratio (OR) $0.21,95 \% \mathrm{CI}-0.10$ to 0.51 ) and drivers identified by reports as being at fault had only one tenth the odds of other occupants of being killed (OR $0.10,95 \%$ CI -0.22 to 0.42 ).

Papers also under-reported the likelihood of restraint use by occupants in fatal crashes. Restraint use was referred to in only $20 \%$ of fatal crashes covered. For 813 occupants described in newspaper stories regarding 278 crashes, papers specifically reported use or non-use of restraints for 122 (15\%). Of those 122 occupants, only 42 (34\% of occupants whose belt use was reported, or $5 \%$ of all occupants) were reportedly restrained. FARS was 14 times more likely than papers to report that at least one occupant was restrained (OR 13.84, 95\% CI 13.49 to 14.19). Although FARS reported restraint use was low ( $38 \%$ of occupants), it was much higher than that reported by newspapers ( $5 \%$ of occupants).

In addition to under-reporting restraint use, papers significantly misrepresented the safety value of restraints. When analysis was restricted only to the subset of occupants whose restraint use was reported by papers, the odds of restrained occupants surviving were 3.3 times the odds of unbelted occupants (95\% CI 2.56 to 4.12 ), much like the odds reported by FARS (OR 3.62, 95\% CI 3.43 to 3.81). However, when all occupants described in newspaper stories were considered, not merely those whose belt use was reported, the odds of restrained occupants surviving were no higher than the pooled group of occupants who were specifically described as unrestrained and those whose restraint use was not reported (OR 0.93 , 95\% CI .28 to 2.58 ).

Papers significantly underplayed the role of road conditions as potential contributing factors in fatal crashes. FARS reports road surface conditions, but makes no judgments regarding the contribution of road conditions to individual crashes. Dry road surface conditions predominated (79\% of all crashes), but $17 \%$ of fatal crashes took place when roads were wet, $2 \%$ when roads were snowy or slushy, and $1 \%$ when roads were icy. Papers rarely referred to weather or road conditions, however, and only the Journal Sentinel cited road conditions as a possible causal factor for a significant number of crashes (11\%).

Papers over-represented the involvement of teens in fatal crashes. While only $14 \%$ of all fatal crashes in these communities involved a teen driver, $22 \%$ of crashes covered in the four papers involved teen drivers. The odds that a crash reported in a newspaper involved a teen driver was nearly twice the odds that a crash reported in FARS involved a teen driver (OR 1.79, 95\% CI 1.44 to 2.13). The involvement of alcohol in crashes also was over-reported $(z=2.46, p=0.01)$ : $26 \%$ of covered crashes reported alcohol involvement, while only 19\% of all crashes were flagged as alcohol related by FARS. The confluence of teens and alcohol, however, was not over-reported $(\mathrm{z}=-1.36, \mathrm{p}=0.17)$.

The study also examined the synonyms writers employed to describe these fatal events. "Crash" was the primary noun used to describe the incident for all papers except the Plain Dealer, where "accident" predominated. For the combined data set, the mean number of references to "crash" per incident covered was 2.69 (SE 0.20) and the mean number of references to "accident" per incident covered was 2.13 (SE $0.17)$.

\section{DISCUSSION}

\section{Limitations}

This study had several limitations. The search terms utilized may not have captured all fatal crash related stories published in these papers, although the number of missed stories is believed to be negligible. This study provides a representative look at the types of crashes covered and the ways in which information was presented by writers in these markets. Further, the study is not based on a random sample of crash coverage in United States newspapers, but instead on a convenience sample of four cities, representing mid-sized to large-sized markets and providing a cross section of news styles in the United States Midwest.

Additionally, while establishing blame was a key concern for newspaper reporters, "fault" is a fuzzy area in FARS. With the exception of a flag for alcohol or drug involvement which is based on reports filed by responding officers, FARS tracks convictions only, not citations. Further, only convictions 
occurring within the 90 day deadline for states to submit crash data to NHTSA are included. Thus, FARS cannot be used to approximate the number or types of convictions that occur in relation to fatal crashes, precluding comparison of FARS and newspaper data for these variables. For the same reasons, FARS data does not provide an accurate picture of the extent to which speeding, failure to yield, and other driver factors contribute to crashes. This lack of certainty in federal crash data, however, underscores the extent to which the clear cut blame assigned in newspaper stories is a reporting construct, rather than a reflection of official police reports.

\section{Principal findings}

All four papers presented fatal motor vehicle crashes as minidramas, with clearly defined victims and villains. Papers under-represented the proportion of drivers killed in fatal crashes by focusing disproportionately on those crashes in which "at-fault" drivers survived to take the blame. Thus, the choice of stories covered and the narrative strategies employed give readers the impression that the undeserving and unsuspecting are more likely to be killed, while those whose mistakes contribute to crashes are more likely to survive. Papers also displayed a tendency to ignore details that did not have a place in the dramatic narrative, such as occupants' use of restraints or the contribution of poor road conditions.

Word choice was studied as a measure of the messages newspapers promoted about the nature of crashes-are incidents positioned as a confluence of contributing events and factors, as unavoidable acts of fate, or as the culmination of one person's negligence or poor decision making? The terms crash and accident were used roughly interchangeably. Those working in the field of injury prevention often object to the term "accident" because it perpetuates an idea of crashes as unpredictable, unpreventable events and downplays the precipitating role of human action and error. Despite the connotations of the term accident, its use in newspaper articles was seldom accompanied by a neutral stance regarding causality, with nine out of 10 stories assigning blame. The use of the term accident does, however, mesh with newspapers' tendency to promote a victim/villain dichotomy. Drivers and passengers who were not assigned blame were generally portrayed as the unsuspecting victims of forces beyond their control, allowing the event to be simultaneously portrayed as the predictable outcome of one person's negligence and as an unexpected and unavoidable act of fate which took the lives of the innocent.

Crashes involving teenagers could be viewed as more dramatic, and thus more newsworthy, than crashes involving older drivers, which may account for papers' over-representation of teen involvement in fatal crashes. Additionally, crashes involving teen drivers were more likely to be covered with multiple stories than were crashes involving older drivers; most of these stories, however, focused on the grieving of families and school communities, rather than on factors that contributed to the crashes. Nationally, teen crashes are more likely to result from speed and inexperience than from alcohol, which all papers accurately reflected in their coverage of teen crashes. ${ }^{17-19}$ Both Ohio and Illinois had graduated drives licensing systems in place during the study period, although neither state placed restrictions on passengers. Wisconsin's graduated licensing system, which does include restrictions on teen passengers, did not go into effect until September 2000.

References to the restraint use of occupants in fatal crashes were rare in all papers and the majority of references made $(80 / 122)$ were to non-use of restraints. No stories offered any commentary on the role of restraints in protecting motor vehicle occupants or preventing ejection in a crash, including the information only as a passing reference-that is, "police said the driver was not wearing a seatbelt" - that was not incorporated meaningfully into the crash narrative. As reported by newspapers, only $5 \%$ of occupants in motor vehicle crashes were restrained, while FARS described the use of restraints by $38 \%$ of individuals involved in fatal crashes. FARS coverage of fatal crashes indicated that unrestrained occupants had 3.6 times the odds of restrained occupants of being killed, largely due to the increased risk of ejection; as presented by newspapers, however, restrained occupants were no more likely to survive a fatal crash than other occupants and the risk of death to ejected occupants was significantly under-represented. In omitting references to restraint use for the majority of crashes and failing to make a link between lack of restraint use and risk of ejection or death, papers neglected to convey to readers the important role of restraints in protecting occupants in serious crashes.

Fatal crash coverage reviewed in this study followed a storyline of victim and villain, inviting readers to identify with the story's protagonist and distance themselves from the antagonist. The takeaway message for readers is that while crashes could happen to anyone, the kind of person responsible for most crashes is the "other"-someone not like "us". The implication is that as drivers, readers can do little to protect themselves. In the rush to place blame and to make implicit moral judgments about the drinking, sleepy, or inattentive driver lies the distancing of events from the reader's reality. The choice of stories covered and the construction of crash narratives all appear to be designed to provide easy answers: one person's carelessness or recklessness is easier for writers to present dramatically-and for readers to fathom-than a convergence of mistakes or poor choices by multiple parties.

\section{IMPLICATIONS FOR PREVENTION}

Faced with competition from other news formats (particularly the internet) and the increasing fragmentation of public consensus on what constitute key issues and concerns, the field of journalism is struggling with its identity and the need to change its methods and mission in order to remain relevant in the 21 st century. ${ }^{20}{ }^{21}$ Public health professionals who are aware of this discourse can frame their suggestions in ways that allow journalists to see opportunities for creating a new kind of public journalism, one that redefines the media's role in working toward the common good, while still remaining sensitive to journalists' need to capture and retain readers' attention within a story.

Reporters covering motor vehicle crashes may argue that their job is simply to present the facts, not to provide health promotion information. This study, however, indicates that coverage of motor vehicle crashes in these metropolitan areas is far from factual. Injury prevention specialists can lobby reporters to ask questions about details like restraint use and include that information in their stories without asking them to make the paper a bully pulpit for public health. If papers provided accurate, consistent reports on restraint use by surviving and non-surviving occupants in motor vehicle crashes, it could help to change the way readers think about the issue by objectively conveying the fact that unrestrained occupants are far more likely to be killed. Engaging reporters by "selling" them on the concept that a topic like belt use (or non-use) is news in areas with large scale, federally funded safety belt promotion initiatives may also be an area for health promotion practitioners. With years of pro-belt use and "Click It or Ticket" messages delivered through almost every medium, one could ask a reporter how non-use in this environment is not part of the story. 


\section{Key points}

- Newspaper coverage of fatal crashes did not accurately reflect real risk to occupants.

- Creation of a dramatic narrative involved focusing on unrepresentative crashes and unequivocally assigning blame to one of the individuals involved.

- Papers consistently under-reported restraint use and misrepresented the role of restraints in protecting occupants from ejection and death.

- Papers failed to introduce a public health perspective even where appropriate, as in reporting on crashes involving teen drivers.

- Public health professionals have a variety of opportunities to change the way fatal crashes are framed in local newspapers.

Media coverage of crashes in which teens are among the fatalities also represent an opportunity for public health professionals to change the way fatal crashes are framed by local print media. All four papers published editorial pieces in the wake of high profile teen crashes that discussed the role inexperience and immaturity play in placing young drivers at higher risk, yet stories about the crashes that inspired these editorials did not contain this type of information-instead, they adopted a memorial tone and focused on the talents and accomplishments of the deceased teens and the loss to families and communities. Savvy advocates of public health issues can work with local reporters and editors to translate theoretical journalistic concerns about the relevance of print media in contemporary life into concrete action in something as simple as including information on the factors that put teens at increased risk in their coverage of motor vehicle crashes involving young drivers.

Establishing relationships with local journalists can aid public health professionals in promoting a public health framework in newspaper coverage of motor vehicle crashes, inspiring reporters to look at a story in new ways or to ask different kinds of questions. How can injury prevention specialists impact the reporting of crash consequences in their communities? First, start by reading newspapers each day and becoming aware of the language used in the reports. Is the word "accident" used? Are contributing factors included? Do the reports contain references to speed, drugs, alcohol, or restraint use? To whom do the reporters turn for explanation, background, or follow up? Framing of stories goes two ways: while newspaper reporters and editors frame the issue for the readers, traffic safety professionals who are motivated have opportunities to "fine tune" or even re-frame the issue through their media communications. Public health personnel can work with journalists to weave prevention into news stories involving traffic related fatalities and to establish themselves as resources for local journalists who are covering crash stories. Those in the injury prevention field also can use local newspaper coverage of crashes as "teachable moments" by seizing opportunities to do op-eds and press events, or to pitch safety related or survivor stories to engage the media and the public. Whether public health professionals choose to focus on seatbelt use, alcohol use, distracted driving, or other factors affecting the likelihood and survivability of motor vehicle crashes, changing the way reporters consider an issue is a key step in changing the way the public views the topic.

\section{Authors' affiliations}

S M Connor, Department of Pediatrics, Case Western Reserve University and Community Safety and Resource Center, Rainbow Babies and Children's Hospital, Cleveland, Ohio

K Wesolowski, Community Safety and Resource Center, Rainbow Babies and Children's Hospital

\section{REFERENCES}

1 Frost K, Frank E, Maibach E. Relative risk in the news media: a quantification of misrepresentation. Am J Public Health 1997;87:842-5.

2 Dunwoody S, Griffin RJ. Structural pluralism and media account of risks. In: Demers D, Viswarath K, eds. Mass media, social control and social change. Ames: lowa State University Press, 1999:139-58

3 Taylor CA, Sorenson SB. The nature of newspaper coverage of homicide. Inj Prev 2001;8:121-7.

4 Zhu J. Issue competition and attention distraction in agenda setting: a zerosum perspective. Journalism Quarterly 1992;69:825-36.

5 Hilgartner S, Bosk CL. The rise and fall of social problems: a public arenas model. American Journal of Sociology 1988:94:53-78.

6 Centers for Disease Control and Prevention. Web-based injury statistics query and reporting system (WISQARS) [online]. Available at: www.cdc.gov/ ncipc/wisqars (accessed on 3 March 2003)

7 Pan Z, Kosicki G. Framing as strategic action. In: Reese S, Gandy O, Grant A, eds. Framing and public life: perspectives on the media and our understanding of the social world. Mahwah, NJ: Lawrence Erlbaum, 2001:35-66.

8 Reese SD. Framing public life: a bridging model for media research. In: Reese S, Gandy O, Grant A, eds. Framing and public life: perspectives on the media and our understanding of the social world. Mahwah, NJ: Lawrence Erlbaum, 2001:7-32.

9 Sorenson SB, Manz JG, Berk RA. News media coverage and the epidemiology of homicide. Am J Public Health 1998:88:1510-4.

10 Rodgers S, Thorson E. The reporting of crime and violence in the Los Angeles Times: is there a public health perspective? Journal of Health Communication 2001;6:169-82.

11 Dorfman L, Woodruff K, Chavez V, et al. Youth and violence on local television in California. Am J Public Health 1997;87:1311-6.

12 Greenberg M, Wartenberg D. Understanding mass media coverage of disease clusters. Am J Epidemiol 1990;132(1 suppl):S192-5.

13 Brown J, Chapman S, Lupton D. Infinitesimal risk as public health crisis: news media coverage of a doctor-patient HIV contact tracing investigation. Soc Sci Med 1996;43:1685-95.

14 Wallack L, Dorfman L. Television news, hegemony and health. Am J Public Health 1992;82:125-6.

15 Voight B, Lapidus G, Zavoski R, et al. Injury reporting in Connecticut newspapers. Inj Prev 1998;4:292-4.

16 Lowe JB. When doing nothing can cause harm. Inj Prev 2002;8:346

17 Arnett JJ. Developmental sources of crash risk in young drivers. Inj Prev 2002;8(suppl III):ii17-23.

18 Zhang J, Fraser S, Lindsay J, et al. Age-specific patterns of factors related to fatal motor vehicle crashes: focus on young and elderly drivers. Public Health 1998; 112:289-95.

19 Patel DR, Greydanus DE, Rowlett JD. Romance with the automobile in the 20th century: implications for adolescents in the new millennium. Adolesc Med 2000;11:127-39.

20 Meyer P. Public journalism. The proper role of the news media in a democratic society: is it enough simply to cover the news. In: Harper J, Yantek T, eds. Media, profit and politics: competing priorities in an open society. Kent, $\mathrm{OH}$ : Kent State University Press, 2003:21-48.

21 Carey JW. In defense of public journalism. In: Glasser TL, ed. The idea of public journalism. New York: Guilford Press, 1999:46-66. 